\title{
El cambio político en Quintana Roo y el riesgo de la persistencia del equilibrio institucional
}

\section{The political change in Quintana Roo and the risk of the institutional equilibrium persistence}

\author{
doi: http://dx.doi.org/10.32870/ \\ espiral.v24i70.6519
}

\begin{abstract}
Resumen
Este artículo analiza el diseño institucional de Quintana Roo y el cambio político ocurrido en dicho estado en las elecciones estatales del 2016. Se expone que más allá de las causas que llevaron al cambio democrático en el estado estas no resultan determinantes para consolidar el cambio político debido al diseño institucional de origen, que incluye una sociedad burocratizada y dependiente de los agentes del Gobierno. Se concluye que la sociedad de Quintana Roo se enfrenta a una dicotomía: por un lado, busca una mejora en las decisiones del Gobierno estatal, y por otro se resiste a cambiar el equilibrio institucional sobre el que se diseñó la estructura sociopolítica. El análisis se realiza con los aportes teóricos del nuevo institucionalismo y de la democracia subnacional. El trabajo se apoya en entrevistas abiertas a actores clave de la política local.
\end{abstract}

Palabras clave: cambio político, diseño institucional, nuevo institucionalismo, democracia subnacional, Quintana Roo.
Gerardo Hernández*
Keywords: political change, institutional design, New Institutionalism, Subnational Democracy, bureaucratization.

\footnotetext{
- Profesor-Investigador del Instituto de Investigaciones Sociales de la Universidad Autónoma de Baja California (UABC), campus Mexicali, México. ghernandez48@uabc.edu.mx Fecha de recepción: 07 de febrero de 2017. Fecha de aceptación: 27 de marzo de 2017.
} 


\section{Introducción}

El estudio de las transiciones democráticas y el cambio político no es reciente. Estos dos fenómenos, relacionados entre sí, conllevan un cuestionamiento de los arreglos institucionales imperantes. Dichos arreglos dejan de ser funcionales o rentables para una sociedad y esta emprende la búsqueda de un nuevo entramado institucional (Casar, 1989).

Dentro de los grandes estudiosos de las transiciones están Huntington (1991), O’Donnell y Schmitter (1986), Alcántara (1992), Morlino (2005) y Loaeza (1994). Los intereses de cada perspectiva-estudio se han centrado en cómo el proceso de democratización se va implantando en la sociedad, lo que permite que los sectores excluidos tengan acceso a los derechos ciudadanos (O'Donnell y Schmitter, 1986).

La preocupación también ha estado en la conceptualización del proceso democrático, que va desde el cambio político pacífico, gradual, hasta el proceso de legitimación, en el cual se requiere de una participación fundamental de las élites en el poder (Huntington, 1991, p. 583). Este proceso se relaciona con la democratización, la cual tiene que ver con el establecimiento de reglas que regulen el comportamiento de los actores políticos, las organizaciones y la ciudadanía que conforman el nuevo arreglo institucional. No obstante, con el avance de la democracia en el ámbito global, también se ha cuestionado su calidad y crisis. Lo anterior se refiere a la situación que viven los derechos políticos y civiles, así como los mecanismos de participación ciudadana y de competencia política (Morlino, 2005; Loaeza, 1994).

En México, el análisis sobre la democracia ha pasado de la descripción del régimen autoritario a la preocupación por encontrar los factores que impiden la consolidación de la democracia. Aziz Nassif (2003) señala que existen desafíos en el país, como terminar de construir la democracia y 
enfrentar y resolver el cúmulo de problemas en el sistema político. Dicho autor plantea que el hecho de que se tenga una democracia procedimental significa que en el país se ha transitado a la misma de forma desigual y heterogénea, reflejo de la convivencia entre el viejo y el nuevo régimen, así como entre el viejo y el nuevo sistema político. Este escenario complejo es al que se refiere Merino (2003) cuando señala que el estudio de la democracia en México no puede limitarse solamente a lo electoral, esto porque en el proceso de transición ha predominado el poder de las elecciones (democracia procedimental) por sobre otros temas más relevantes, como la generación de reformas políticas que empoderen a la ciudadanía.

El escenario descrito y la preocupación existente se han acentuado aún más porque la transición democrática a nivel nacional ha sido vista como uno de los grandes avances de la vida política en el país. El triunfo de un partido opositor (PAN) sobre el partido hegemónico (PRI) en el año 2000 fue resultado de un proceso intermitente que inició en otras entidades federativas, específicamente cuando el Partido Acción Nacional (PAN) ganó la gubernatura de Baja California, en 1989. No obstante, esta ola democrática no se extendió a la mayoría de los Gobiernos subnacionales: hasta las elecciones estatales de 2016, y desde 1929, los Gobiernos subnacionales de Veracruz, Durango, Coahuila, Tamaulipas y Quintana Roo habían sido gobernados por el Partido Revolucionario Institucional (PRI) (los estados de Campeche, Colima, Hidalgo y Estado de México continúan siendo gobernados por el PRI).

Esta paradoja democrática permite cuestionar las razones de la persistencia de los equilibrios institucionales en el tiempo, cómo logran romperse y sus alcances. En este mismo sentido, algunos estudios sobre democracia subnacional (Arellano, 2014a; Campos, 2012; Gervasoni, 2011; Gibson, 2007; Acosta, 2004; Aziz Nassif y Alonso Sánchez, 2003; 
Ibarra, Sandoval y Sotres, 2001) señalan que los cambios políticos en las regiones no han implicado un escenario de consolidación democrática. Esto quiere decir que mientras las transiciones democráticas llegaron a nivel nacional, los presidentes, y en general los nuevos Gobiernos, tuvieron que atender una serie de demandas propias de la vida en democracia, generando una ambivalencia política: por un lado se buscó consolidar la democracia a nivel nacional, y por otro los Gobiernos estatales establecieron enclaves autoritarios lejos del alcance de la política nacional.

Es importante señalar que el estudio de los Gobiernos subnacionales no es nuevo, y que el interés sobre el mismo ha crecido de manera paulatina. El análisis también se puede hacer desde la perspectiva de las instituciones, como lo han hecho Arellano (2014b) y Acosta (2004). De esta manera, el estudio de la permanencia de los equilibrios institucionales y del cambio político en los Gobiernos subnacionales se reconoce como una herramienta para el estudio de estos en el nuevo institucionalismo.

El argumento del nuevo institucionalismo (Skoopol, 1992; King, 1995, citado en Peters, 2003; Evans, Rueschemeyer y Skoopol, 1979; Steinmo, Thelen y Longstreth, 1992) plantea que las decisiones que toman los agentes en el Gobierno para formar instituciones o iniciar actividades generalmente tienen una influencia prolongada y definida sobre la política, lo que ocasiona que persistan a través del tiempo.

Por otra parte, el cambio político también se explica desde la perspectiva de quienes controlan el entramado institucional. Para que suceda el cambio institucional, debe haber rentabilidad en el nuevo equilibrio entre instituciones, que se presenta, por ejemplo, en la durabilidad de las nuevas instituciones, un factor que condiciona el apoyo de los grupos de interés (Rowley, 1993; North, 1993; Moe, 1990). Es necesario puntualizar que este enfoque no está separado de la manera en que los especialistas en temas de democra- 
cia han analizado los cambios políticos en las sociedades, por el contrario, el nuevo institucionalismo y el análisis de los actores y diversas coyunturas o puntos de quiebre que definen las trayectorias históricas de las sociedades ayudan a comprender el conflicto que origina el proceso de creación de instituciones. A partir de ello, dicho enfoque contribuye al estudio de los Gobiernos subnacionales.

El objetivo de este texto es estudiar la persistencia y el cambio político en Quintana Roo, entidad federativa que fue gobernada por el PRI desde su fundación como estado libre y soberano, en 1974, hasta las elecciones estatales de 2016, cuando una alianza opositora (PAN-PRD) logró derrotar al PRI en el Gobierno del estado y en el Gobierno del municipio de Othón P. Blanco (que alberga la capital del estado, Chetumal).

Se puede afirmar que el proceso de alternancia en Quintana Roo inició en realidad en el año 2002, con el cambio de partido en el Gobierno del municipio de Benito Juárez (donde se encuentra Cancún), al que siguieron alternancias en los municipios de Cozumel, Isla Mujeres, José María Morelos, Lázaro Cárdenas y Felipe Carrillo Puerto. Cabe señalar que el cambio político en los municipios ha sido intermitente, es decir, el PRI ha sido derrotado y reinstaurado en los poderes municipales sin que los Gobiernos de alternancia hayan podido responder a las demandas ciudadanas que los llevaron al poder.

Se plantea como hipótesis de trabajo que las razones que condujeron al cambio político en el Gobierno de Quintana Roo, como la corrupción de la clase política, la deuda pública y el descontento con la calidad e impacto gubernamentales, no son variables determinantes para que el nuevo Gobierno consolide el cambio institucional del estado. Lo anterior se debe al diseño institucional de origen, manifestado en una sociedad burocratizada y dependiente de los agentes del Gobierno, la cual se enfrenta a una dicotomía: por un 
lado, dicha sociedad busca una mejora en las decisiones del Gobierno estatal, y por otro se resiste a alterar el equilibrio institucional sobre el que se diseñó la estructura sociopolítica del Gobierno del estado.

Es necesario señalar que los estudios que abordan el diseño institucional como fuente de la persistencia del poder político en Quintana Roo son prácticamente nulos. Esto no significa que no haya investigaciones reconocidas sobre la democracia en los Gobiernos subnacionales. Los trabajos de Acosta (2004), Aziz Nassif y Alonso Sánchez (2003) y Arellano (2014a; 2014b) son referentes para entender la complejidad del fenómeno. Como se ha mencionado, la alternancia en el país inició en las regiones y se extendió al nivel federal, pero esto no significó la consolidación democrática, ni garantías para un cambio en la cultura política (Aziz Nassif y Alonso Sánchez, 2003).

No sólo falta un cambio en la cultura política, sino también en la manera en que se diseñan e implementan las políticas públicas. Sin embargo, se puede afirmar que se ha dado una alteración de las rutinas y comportamientos de la distribución del poder, es decir, Gobiernos divididos y sin mayoría en los congresos locales (Acosta, 2004). Este escenario, más allá de ser un síntoma positivo de la democracia en los Gobiernos subnacionales, termina por afectar la gestión y la coordinación entre Gobiernos.

Arellano (2014a) señala, a partir del análisis de las zonas metropolitanas, que cuando una urbe está fuera de control es una cuestión de factores políticos y de diseño institucional, y no de planeación. Por tal motivo, como argumenta Alcántara (1992, pp. 36-38) al analizar las transiciones (aunque el autor lo hace sobre países), es simplista construir un modelo que recoja la idea de que una transición política es seguida infaltablemente por un periodo de consolidación del régimen político. 
Esta falta de simplicidad en las alternancias es lo que vuelve interesante estudiar la particularidad de los cambios políticos en los Gobiernos subnacionales. Para el caso de Quintana Roo, que experimenta por primera vez una alternancia, la presente investigación intenta dar una lectura sobre cómo se ha dado el cambio político sin que dicho cambio signifique la llegada a una consolidación democrática.

En este mismo sentido, imperan valiosas investigaciones que hacen un recuento de la conformación del estado de Quintana Roo desde la perspectiva jurídica, antropológica, histórica y desde la sociología política, como las de Samaniego (2010), Careaga e Higuera (2011), Camal (2013) y Macías (1997), las cuales, sin embargo, no retoman de manera directa el tema de las decisiones que la clase política ha implementado durante la historia de la trayectoria institucional del estado. Inclusive el trabajo de Camal (2013) termina por forzar el plano teórico del estudio de las élites en Quintana Roo. Todo esto se menciona porque sólo se puede hablar de una élite que ha sido determinante en el rumbo institucional del estado, y no de una pluralidad de estas.

El trabajo se divide en cinco secciones. La primera expone los referentes teóricos y las características políticas de los Gobiernos subnacionales, así como los aportes del nuevo institucionalismo para el análisis de las instituciones en tanto elementos de conformación del poder político, su path dependence (dependencia del rumbo) y las fuentes que originan las resistencias y el cambio político. En la segunda sección, se describen brevemente los antecedentes de la creación del estado de Quintana Roo, lo cual ayuda a comprender cómo se inició el diseño institucional del estado. En el tercer apartado, se analiza el cambio de territorio federal a estado en el caso de Quintana Roo para comprender el diseño de la trayectoria institucional, la persistencia del equilibrio político y las causas que produjeron el cambio político en 
la elección estatal de 2016. De igual forma, se analizan los factores institucionales que han ocasionado las alternancias políticas en los municipios, aunque estos de manera recurrente han retornado al equilibrio político antecesor. En la cuarta sección se analizan los riesgos a los que se enfrentan el cambio político y la nueva trayectoria institucional. Se hace alusión a los valores como instituciones osificadas en la sociedad quintanarroense, lo cual representa posibles resistencias al cambio político. Esta sección y la anterior se apoyan en entrevistas abiertas a personajes de la clase política y empresarial en la entidad. En la última sección se presentan las conclusiones.

\section{Gobiernos subnacionales y trayectoria institucional:} bases de la persistencia y el cambio político

La democracia subnacional ha tenido procesos intermitentes en México, cuya explicación necesariamente se relaciona con la particularidad de sus contextos y sus trayectorias institucionales. Como bien señala Campos (2012, p. 24), el proceso de democratización inició en las regiones, pero los alcances más determinantes se apreciaron a nivel nacional, y desde su inicio ha habido un constante trabajo por reformar el sistema legal y electoral para permitir la competencia y la pluralidad políticas. Asimismo, el estudio de estos cambios políticos ha atribuido la existencia de dichos cambios, en un primer momento, al incremento de la clase media y a una atomización -sin que haya desaparecido por completo-del poder presidencial (Campos, 2012, p. 25).

Ante esto, lo que hace falta explicar es por qué ciertos contextos subnacionales, a pesar de los grandes avances democráticos a nivel nacional, no han logrado modificar sus estructuras institucionales. Gibson (2007, p. 165) plantea al respecto que algunos Gobiernos subnacionales no acusan cambios en sus estructuras por la forma en que conducen su 
política territorial. Lo anterior no se refiere al territorio en sí, sino a cómo la política se organiza y se ajusta a través del territorio. De ahí la pertinencia de considerar los aportes del nuevo institucionalismo, el cual plantea la importancia del estudio de los agentes, grupos o individuos que crean instituciones que inciden en el presente y el futuro de las sociedades y determinan su desarrollo.

Desde esta perspectiva, institución se entiende como "los procedimientos formales o informales, rutinas, normas y acuerdos incrustados en la estructura organizativa de la política o de la economía política" (Hall y Taylor, 1996, p. 938). De igual manera, North (1993) la define de la siguiente forma:

Las instituciones son las reglas del juego de una sociedad o, más formalmente, son las limitaciones ideadas por el hombre que dan forma a la interacción humana. Por consiguiente, estructuran incentivos en el intercambio humano, sea político, social o económico. Las instituciones reducen la incertidumbre por el hecho de que proporcionan una estructura a la vida diaria (pp. 13-14).

Evans, Rueschemeyer y Skoopol (1979), Steinmo, Thelen y Longstreth (1992) y Peters (2003) argumentan que las decisiones políticas que se acuerden al formar una institución o al iniciar su actividad tendrán una influencia prolongada y definida sobre la política dominante. Lo anterior toma relevancia mayor porque la manera en que las instituciones inciden o tienen una trayectoria prolongada en una sociedad se debe en gran medida a los agentes que las diseñan. La formulación de políticas institucionales se caracteriza por periodos de tiempo prolongados y de considerable rentabilidad, lo que es denominado path dependence (dependencia del rumbo) (Peters, Pierre y King, 2005). De manera más específica: 
[...] una vez que los Gobiernos crean su política inicial y toman sus decisiones institucionales en determinada área de políticas de gobierno, las normas creadas persisten, a menos que exista una fuerza capaz de superar la inercia creada al ponerse en práctica el programa. En el institucionalismo histórico esto se conoce como la "path dependence". Dado que las organizaciones públicas tienden, tal vez con mayor frecuencia que las del sector privado, a convertir sus actividades en rutina y a crear procedimientos operativos estándares, la fuerza de la inercia suele ser importante en el Gobierno (Peters, 2003, p. 101).

Desde esta perspectiva, los grupos locales de los Gobiernos subnacionales plantean la política territorial con la finalidad de aislar a sus provincias y resistir las presiones democratizadoras provenientes del centro, por ello es que los enclaves autoritarios emergen en países que están democratizando sus instituciones (Gibson, 2007, pp. 168-169). El costo de formar este tipo de reglas es el de los bajos niveles de democracia, y el esquema federalista ha jugado un papel fundamental en este equilibrio inadecuado. Sin embargo, Thelen (1999) menciona que este tipo de equilibrios es consecuencia de los momentos cruciales de la fundación institucional y determina la ruta de desarrollo de las sociedades y países.

Esto quiere decir que el diseño institucional puede ser adecuado y útil en un momento determinado para una sociedad o país, pero luego puede convertirse en un impedimento para el éxito de las sociedades debido a que las instituciones y las ideas que motivaron su creación se osifican con el tiempo en las visiones del mundo de los agentes que participan en ellas, dificultando el cambio institucional (Hall, 1986). Debido a la clientela profundamente arraigada y a los intereses burocráticos involucrados en la solución de un problema en particular, este proceso puede generalizarse más en los proyectos de políticas (Peters, Pierre y King, 2005).

En el caso de México, el federalismo no necesariamente es un sistema construido bajo el precepto de la cooperación,

\section{4}


sino un sistema vertical y de control en el que por mucho tiempo los Gobiernos subnacionales estuvieron destinados a acatar las disposiciones del centro. Uno de los elementos de control hacia los Gobiernos subnacionales ha sido el subsidio fiscal del Gobierno nacional, que ha tenido como consecuencia una dependencia financiera excesiva que ha representado una limitación para la autonomía de los Gobiernos subnacionales al impedir la responsabilidad fiscal (Ibarra, Sandoval y Sotres, 2001, p. 28). Por otro lado, estos subsidios han generado discrecionalidad en la toma de decisiones, es decir, la formación de equilibrios imperfectos, los cuales han permitido a los gobernantes locales no cobrar impuestos a los ciudadanos, lo que disminuye los incentivos y el poder de estos para participar en el poder político. Cuando el Gobierno subnacional domina la economía local, los actores sociales son menos autónomos y políticamente menos exigentes, es decir, los ciudadanos tienden a subordinarse, los activistas y políticos se suman al partido gobernante y la oposición tiene dificultades para encontrar seguidores (Gervasoni, 2011, p. 584).

Este tipo de equilibrios institucionales inadecuados, como bien señala el nuevo institucionalismo, tienen una influencia prolongada y definida sobre la política dominante. La consecuencia de este tipo de prácticas no democráticas conlleva la probabilidad de que un mismo partido político gobierne por periodos muy extensos y tenga amplias mayorías electorales y un abrumador control del Poder Ejecutivo sobre el Legislativo (Gervasoni, 2011, p. 590). Sin embargo, esto no significa que las instituciones no generen cambios o reformas. Los nuevos objetivos asignados a las instituciones tienen la finalidad de mantener el equilibrio institucional que favorece a los agentes que las diseñaron y que las controlan (Peters, Pierre y King, 2005).

Lo anterior alude a la dicotomía de que mientras a nivel nacional se busca consolidar la democracia, los Gobiernos 
subnacionales tienen la presión por mantener niveles mínimos de ella, aunque esto no necesariamente significa romper los enclaves autoritarios rentables políticamente. Gervasoni (2011, p. 590) menciona que lo anterior se refiere a que las elecciones se llevan a cabo y el recuento de votos es limpio, pero los gobernantes gastan mucho más que sus opositores, y los medios locales, aunque formalmente independientes, son comprados para sesgar la cobertura en favor del partido oficialista. El autor señala que la discrecionalidad es precisamente lo que incentiva a realizar este tipo de prácticas antidemocráticas difíciles de medir, aunque sus efectos sobre los resultados políticos son más susceptibles a la observación empírica.

\section{I. Cambio institucional}

La interrogante que surge ante la path dependence del diseño institucional de los Gobiernos subnacionales es cómo explicar la fractura de estos equilibrios y su paso a un nuevo equilibrio político que, sobre todo, esté al alcance de dichos Gobiernos. De acuerdo al nuevo institucionalismo, la respuesta a esta pregunta podría encontrarse en la dosis de presión política que puede ejercer el grupo de agentes que persiguen el cambio institucional (Peters, 2003). Dicha presión se materializa en el conflicto político entre agentes. Por un lado, el nuevo arreglo institucional debe ser lo suficientemente rentable para que los agentes apuesten por el conflicto político. Por otro lado, estarán los agentes o coaliciones -incluida la ciudadanía- que pondrán resistencia al cambio y defenderán el curso político de las instituciones (Peters, Pierre y King, 2005).

Como bien señala Gibson (2007, p. 173), un conflicto en un Gobierno subnacional se nacionaliza cuando actores externos se alían con oposiciones locales, invierten recursos en la jurisdicción y se convierten en participantes de la lucha por el poder. Una vía a través de la cual se logra esto es la

\section{6}


identificación de una crisis local en la que la oposición eleve el conflicto hasta los actores nacionales y logre articularlo en lo local con los intereses políticos o territoriales de dichos actores. La finalidad de esta nacionalización del conflicto local es el control de las instituciones y el poder político. Para el nuevo institucionalismo, las instituciones son "armas de coerción y redistribución. Son los medios estructurales mediante los cuales los ganadores políticos persiguen sus propios intereses, frecuentemente a expensas de los perdedores políticos" (Moe, 1990, p. 213). En los Estados democráticos, la política tiene que ver fundamentalmente con el ejercicio de la autoridad pública (instituciones) y la lucha para ganar el control de dicha autoridad. Quien ejerce el control tiene el derecho a imponer a los demás qué hacer o no hacer. En este sentido, habrá actores, grupos o coaliciones que quedarán mejor posicionados que otros (Moe, 1990, p. 213).

Sin embargo, es importante mencionar que el resultado dependerá en gran medida del poder político de cada grupo, y sobre todo del contexto social, económico y político en el que las ideas del cambio institucional se encuentren, es decir, la fuerza de los factores exógenos es una variable que se debe considerar (Peters, Pierre y King, 2005).

Se hace hincapié en los factores externos debido a que pueden generar consecuencias no intencionadas que conduzcan el cambio institucional a una trayectoria no esperada (Thelen, 1999). Ante esto, siempre está la posibilidad de la negociación de los diferentes grupos en disputa, lo que podría llevarlos a mantener el mismo arreglo institucional debido a las dificultades de establecer e implementar nuevas reglas.

\section{Antecedentes de la creación del estado de Quintana Roo}

La formación institucional del estado de Quintana Roo, como todo proceso histórico, ha sido compleja, sobre todo 
porque los eventos políticos del centro del país impactaron de manera significativa el desarrollo político, social y económico de dicho territorio del sureste mexicano. En México, al concluir la Guerra de Independencia con España, en 1821, la provincia de Yucatán abarcaba la totalidad de la península del mismo nombre. No obstante, el crecimiento poblacional de los asentamientos humanos dentro de este territorio hizo complejo el mantenimiento del orden político y económico, y en 1862 se creó el estado de Campeche (Careaga e Higuera, 2011).

Está decisión política no significó tener más medios para someter a los mayas rebeldes -quienes se oponían a la intromisión de las autoridades en sus comunidades-de la parte oriental de la península de Yucatán. El 24 de noviembre de 1902, el presidente Porfirio Díaz creó el territorio federal de Quintana Roo (Gobierno del estado de Quintana Roo, 2015). ${ }^{1} \mathrm{Al}$ tener esa condición jurídica, el Gobierno local se regía por las leyes y disposiciones del Distrito Federal -es decir, el Código de Procedimientos Civiles, el Código Penal y la Ley sobre Contribuciones- (Careaga e Higuera, 2011). La organización política y las incipientes instituciones estuvieron a cargo del primer jefe militar, José María de la Vega, quien no sólo distribuyó el territorio en distritos (Norte, Centro y Sur), sino que otorgó cargos públicos a las autoridades mayas tradicionales (Careaga e Higuera, 2011). Esto sirvió en un primer momento para controlar a los mayas rebeldes y, sobre todo, para mantener un equilibrio político en el territorio (Romero y Rioja, 2012).

\section{I. Definiendo la trayectoria institucional}

En 1931, el Gobierno federal decidió que el mantenimiento del territorio federal de Quintana Roo representaba 
una enorme carga económica para la federación, además de tener escasa población. Por tal motivo, el 19 de diciembre de ese año se publicó en el Diario Oficial de la Federación una reforma al artículo 43 y una adición del artículo 45 constitucionales, con las cuales se desaparecía dicho territorio federal para anexarlo a los estados de Campeche y Yucatán (Samaniego, 2010). Sin embargo, meses antes de que se diera a conocer esta medida, específicamente el 6 de octubre del mismo año, en la capital Payo Obispo, al igual que en Santa Cruz de Bravo, Cozumel e Isla Mujeres, se organizó el Comité Proterritorio de Quintana Roo. La demanda del comité fue detener el cambio jurídico del territorio, pero dicha exigencia no tuvo frutos debido a que las decisiones eran tomadas desde el centro del país, sin consultar a los residentes.

Lo que es importante rescatar es que la organización de este grupo de agentes se debió en parte a los pequeños grupos empresariales (concesionarios para la explotación de la madera y el chicle y comerciantes) que buscaban influir en las decisiones del Gobierno local. La decisión que tomó el Gobierno federal fue producto de la caída del precio del chicle debida a la depresión mundial de 1929 -aunque ese mismo año la producción chiclera obtuvo un récord de 2500000 kg-. Aun así, el comité mantuvo su lucha hasta que durante la visita del candidato presidencial Lázaro Cárdenas, en 1934, este se comprometió a devolver el estatus de territorio a Quintana Roo, lo que ocurrió en 1935 (Careaga e Higuera, 2011).

En ese mismo año fue nombrado como gobernador Rafael E. Melgar, quien a su vez iniciaría una nueva forma de organización política de los grupos al interior del territorio, es decir, el movimiento cooperativista, que buscaba encauzar a los gremios obreros y campesinos (Careaga e Higuera, 2011). Esta forma de organización también sirvió para fomentar el corporativismo y el control político de la clase 
gobernante sobre los habitantes del territorio. Lo expuesto se relaciona con lo planteado por Samaniego (2010), sobre que el territorio continuó sin ser democrático y que se manifestó menosprecio hacia la vida de sus habitantes, lo que se recrudeció con la llegada del gobernador Margarito Ramírez (1944-1958), quien estuvo quince años en el poder.

Por esto, los nuevos grupos de organizaciones civiles buscaron repetir la fórmula del primer comité proterritorio, pero añadiendo a su exigencia la demanda de tener un gobernador originario de Quintana Roo. De esta manera, y durante el periodo de 1946 a 1956, se originaron una serie de los llamados movimientos nativistas en el territorio. El primero de estos se suscitó en Cozumel en 1946 con el denominado Comité Progobernador Nativo del Territorio, al que seguirían, en 1948, el Núcleo Salvador del Pueblo de Quintana Roo, el Frente Renovador Quintanarroense y el Comité Prodefensa Territorial de Quintana Roo, y, en 1956, el Frente Cívico Quintanarroense (Samaniego, 2010; Careaga e Higuera, 2011).

Sin embargo, los agentes encargados de la vida política del territorio federal no tenían capacidad para satisfacer las demandas de los grupos locales. Esto se debió a lo funcional del equilibrio social y político que definió una path dependence en ese momento, un equilibrio que había sido determinado por la historia del territorio federal. Esto quiere decir que los encargados de la política local establecieron un enclave autoritario en el que no había evidencia de vida democrática ni participación ciudadana.

Ante esto, la oposición (los grupos nativistas) buscó nacionalizar el conflicto para negociar un nuevo arreglo institucional. Como no lo consiguieron, los grupos nativistas modificaron sus exigencias y solicitaron ser incorporados al aparato burocrático del Gobierno con el argumento de que, al ser residentes, ellos sí conocían las necesidades locales (Careaga e Higuera, 2011). Esta última petición se convir- 
tió en una de las exigencias más representativas de todo el movimiento político que se desarrollaría, sobre todo en el sur del territorio federal, ante la falta de interés por parte del Gobierno local y federal de atender la demanda por un gobernador nativo.

Dicha petición resultaba necesaria porque no existía otra forma de romper el equilibrio impuesto por las autoridades. Ni los factores exógenos, como el huracán Janet, que destruyó la capital en 1955, ni las denuncias contra la corrupción del gobernador Margarito Ramírez (que incluían acusaciones por tala y exportación a Belice de árboles de manera fraudulenta) fueron motivo para que las autoridades federales tomaran en cuenta a los residentes. El último recurso se encontraba en la voluntad política, y fue a través de ella que, durante la presidencia de Adolfo López Mateos (1958-1964), se nombró a Aarón Merino Fernández como gobernador del territorio y se permitió la formación de cuadros políticos para la administración pública local, además de fomentarse otra serie de políticas como la inmigración masiva para incrementar la población (Careaga e Higuera, 2011).

Aunado a esto, en 1959 el Gobierno federal implementó la política de perímetros de zona libre, sobre todo para el sur del territorio. Con esta medida se facilitaba la llegada de alimentos y mercancías, y sobre todo se buscaba la capitalización de los comerciantes y mejorar la calidad de vida de los habitantes (Careaga e Higuera, 2011). El resultado de este tipo de políticas no necesariamente fortaleció a los comerciantes para convertirlos en una clase empresarial que fuera un contrapeso del poder político.

Un escenario distinto ocurrió en el norte del territorio, que desde 1959 empezó a dar señales de lo que sería la industria del turismo masivo. A inicios de la década de 1960, sobresalió la figura del empresario Nassim Joaquín, quien administraba los únicos dos hoteles de la isla de Cozumel, 
además de tener conexión con la aerolínea Mexicana de Aviación. ${ }^{2}$ En Isla Mujeres sucedió lo mismo con el empresario turístico José de Jesús Lima. Para 1970, Cozumel e Isla Mujeres contaban con diecisiete y diecinueve hoteles, respectivamente, con una oferta total de seiscientas cincuenta y cinco habitaciones. El pujante crecimiento de esta industria llevó al Gobierno federal a plantear el nacimiento de la ciudad de Cancún, en 1975, para impulsar la economía regional y aumentar los ingresos nacionales (Careaga e Higuera, 2011).

Por otro lado, en el sur del territorio, hacia 1961, los hijos de los residentes que tuvieron el acceso a estudios universitarios fuera del territorio (sobre todo en la Ciudad de México) regresaron para conformar la incipiente clase política y retomaron el movimiento nativista. Entre dichos jóvenes estaban Jesús Martínez Ross, Ismael Araulo y Carlos Gómez Barrera, los cuales fundaron la Fraternidad Quintanarroense, A. C.; también surgieron la Unión Cívica y Social de Chetumal y la Sociedad de Estudiantes Quintanarroenses en la Ciudad de México. La exigencia de estos grupos organizados fue la de obtener mayor cantidad de puestos en el aparato burocrático, algo que fue concedido por el gobernador Rufo Figueroa (1965-1967). Lo mismo sucedió durante el periodo de Gobierno de Javier Rojo Gómez (1967-1970), cuando la Secretaría General de

2. La incursión del empresario Nassim Joaquín en la hotelería fue austera hasta que recibió la concesión del Hotel Playa. Después, Joaquín invirtió en los búngalos Playa Azul y construyó los hoteles Playa Azul y Cozumeleño. De esta manera, el desarrollo económico del empresario involucró la hotelería, los bienes raíces y la distribución de combustibles, algo que se compaginó con la incursión de la familia de Joaquín en la política del estado. Por ejemplo, Pedro Joaquín Coldwell, su hijo, fue diputado local (1975-1978) y luego gobernador del estado (198I-1987), su hija Addy Joaquín Coldwell diputada y senadora, Carlos Manuel Joaquín González presidente municipal de Solidaridad entre 2005 y 2008, y Gustavo Ortega Joaquín y Aurelio Joaquín González presidentes municipales de Cozumel en los periodos 2005-2008 y 20 I I-20 I3, respectivamente (Redacción, 2014). 
Gobierno fue ocupada por el nativo Miguel Mario Angulo Flota (Samaniego, 2010).

\section{Diseño y persistencia del equilibrio institucional en Quintana Roo}

En 1974, el territorio federal se encaminaba a convertirse en estado libre y soberano cuando el entonces presidente Luis Echeverría Álvarez (1970-1976) presentó la iniciativa de reforma de los artículos 43 y 45 constitucionales para elevar a la categoría de estado a los territorios de Quintana Roo y Baja California, medida que no encontró oposición en las legislaturas estatales.

De esta manera, el gobernador David Gustavo Gutiérrez (1971-1974) se encargó de convocar a elecciones para conformar el congreso constituyente. En el Cuadro 1 se aprecian los nombres de los diputados participantes y su distrito representado. Cabe señalar que todos los diputados eran priistas. Además, como presidente del congreso se eligió a Pedro Joaquín Coldwell, entonces de 24 años de edad (Samaniego, 2010).

Cuadro 1. Congreso constituyente de 1974-1975

\begin{tabular}{lll} 
Distrito & Diputado & Partido político \\
Primer distrito & Mario Bernardo Ramírez Canul & PRI \\
Segundo distrito & Alberto Villanueva Sansores & PRI \\
Tercer distrito & Abraham Martínez Ross & PRI \\
Cuarto distrito & José Flota Valdez & PRI \\
Quinto distrito & Sebastián Estrella Pool & PRI \\
Sexto distrito & Pedro Joaquín Coldwell & PRI \\
Séptimo distrito & Gilberto Pastrana Novelo & PRI \\
\hline
\end{tabular}

Fuente: elaboración propia con datos de Careaga e Higuera (2011).

Asimismo, se conformaron siete municipios: Benito Juárez, Cozumel, Felipe Carrillo Puerto, Isla Mujeres, José María 
Morelos, Lázaro Cárdenas y Othón P. Blanco. Décadas más tarde se crearían cuatro municipios más: Solidaridad, Tulum, Bacalar y Puerto Morelos (Periódico Oficial del Estado de Quintana Roo, 2015). De esta manera, las bases para el desarrollo político del estado estaban dadas.

Este proceso transcurrió a través de instituciones formales e informales con las cuales se afianzó el control político del PRI por medio del corporativismo, el clientelismo (el establecimiento de cooperativas forestales y perímetros de zona libre) y las prebendas, creando un enclave autoritario que definiría una trayectoria institucional arraigada en la estructura sociopolítica del estado. Este tipo de equilibrios, de acuerdo con la teoría, incrementa la probabilidad de que los periodos del control del poder político se mantengan en un único partido (Gibson, 2007). Por ejemplo, desde 1975 hasta 2016, los siete gobernadores de Quintana Roo emanaron del PRI sin que existiera oposición o riesgo de perder el control político. En el Cuadro 2, se aprecian los gobernadores que ha tenido la entidad desde su conversión en estado libre y soberano, así como el porcentaje de votación en cada elección.

Cuadro 2. Gobernadores de Quintana Roo (1974-2015)

\begin{tabular}{lccc} 
Gobernador & $\begin{array}{c}\text { Periodo de } \\
\text { gobierno }\end{array}$ & $\begin{array}{c}\text { Partido } \\
\text { político }\end{array}$ & $\begin{array}{c}\% \text { de } \\
\text { votación }\end{array}$ \\
Jesús Martínez Ross & $1975-1981$ & PRI & $98.94 \%$ \\
Pedro Joaquín Coldwell & $1981-1987$ & PRI & $96.23 \%$ \\
Miguel Borge Martín & $1987-1993$ & PRI & $95.88 \%$ \\
Mario Villanueva Madrid & $1993-1999$ & PRI & $91.93 \%$ \\
Joaquín Hendricks Díaz & $1999-2005$ & PRI & $44.39 \%$ \\
Félix Arturo González & $2005-2011$ & PRI-PVEM & $41.66 \%$ \\
Canto & & & \\
Roberto Borge Angulo & $2011-2015$ & PRI-PVEM-PANAL & $55.84 \%$ \\
\hline
\end{tabular}

Fuente: elaboración propia con datos del IEQROO (Instituto Electoral de Quintana Roo) (2016a). 
El control político del PRI no sólo implicó la gubernatura estatal, sino también las legislaturas, y como se mencionó, esto no representó profesionalizar una clase política ni el desarrollo de una ciudadanía política en el estado. En lo que se refiere al control de las legislaturas, el PRI mantuvo una trayectoria en la que desde 1974 hasta 1999 no hubo oposición. Los pocos espacios de oposición política llegaron únicamente por vía plurinominal en la legislatura de 19781981, a través de los partidos PPS y PARM (Ver: Gráfica 1). Fue hasta la legislatura 1996-1999, veintidós años después, que un partido de oposición, el PAN, ganó su primer escaño por vía de los votos.

Gráfica 1. Legislaturas en Quintana Roo. Periodo 1974-1999

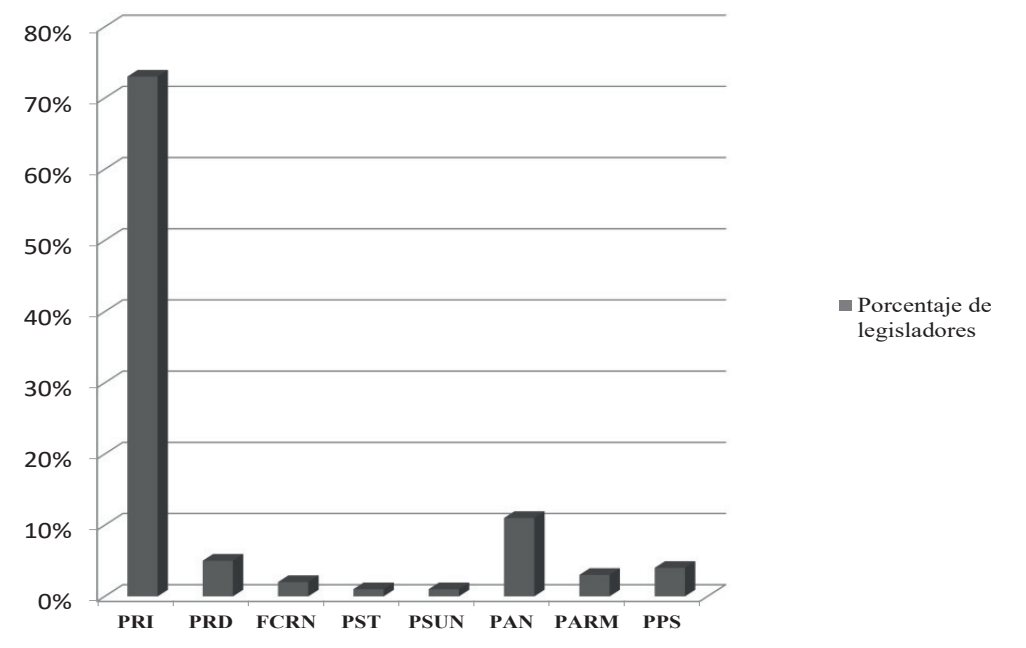

Fuente: elaboración propia con datos del Congreso del Estado de Quintana Roo (2016).

Es importante señalar que con la llegada de la alternancia democrática a nivel nacional, en el año 2000, el control del PRI no se modificó en Quintana Roo. En la Gráfica 2 se 
observa el porcentaje de control del PRI y la oposición en las legislaturas hasta 2016.

Gráfica 2. Legislaturas en Quintana Roo (1999 a 2016)
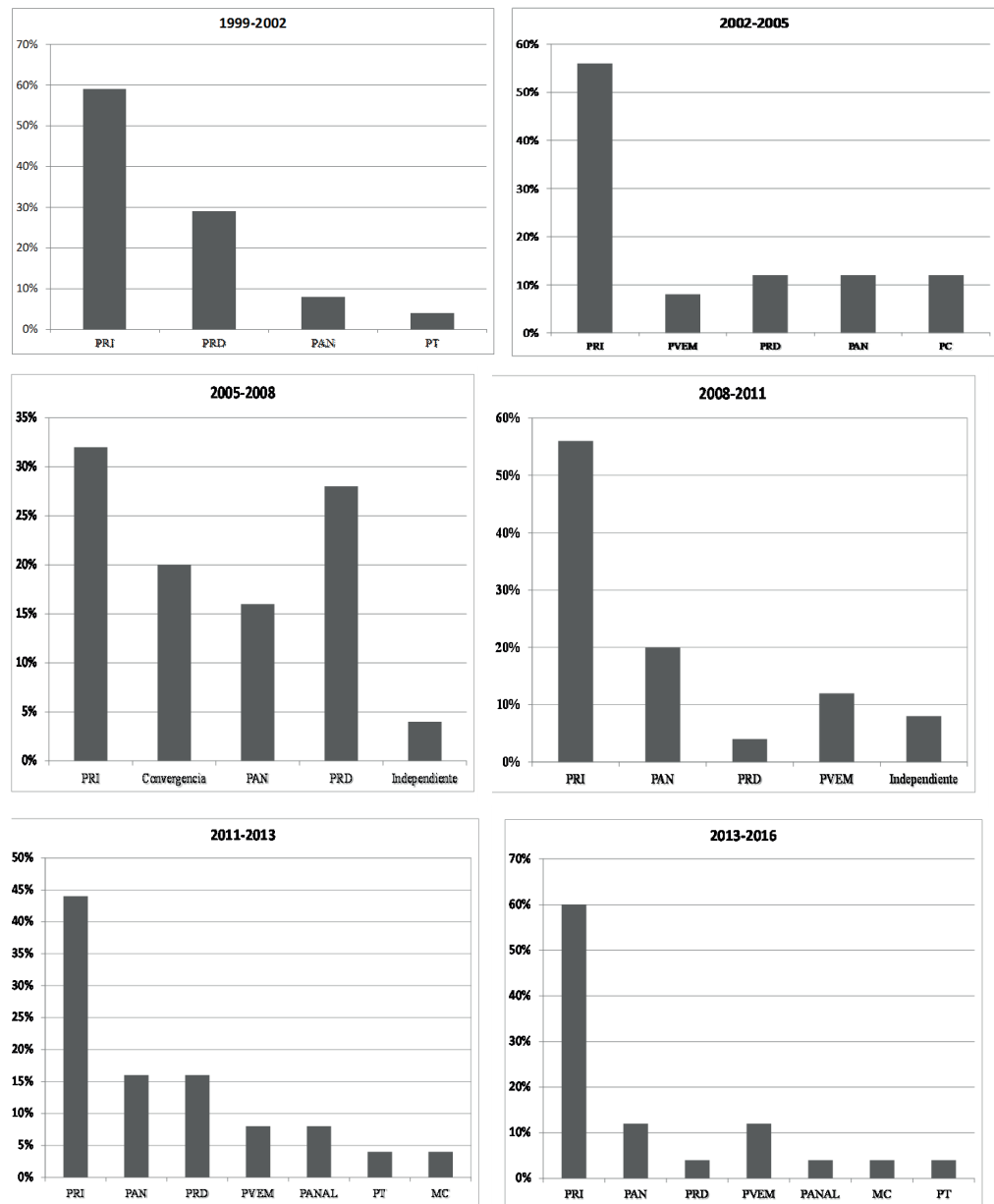

Fuente: elaboración propia con datos del Congreso del Estado de Quintana Roo (2016). 
Cabe señalar que en las elecciones para gobernador de 2005 -en las cuales resultó ganador el candidato del PRI, Félix González Canto-, el PRI por primera vez perdió la mayoría en el Congreso local (legislatura 2005-2008) al obtener únicamente ocho diputaciones (dos de ellas plurinominales), contra diecisiete curules de oposición. No obstante, para las elecciones intermedias de ese mismo sexenio, el PRI volvió a obtener el control del Congreso local con el 56\% de los escaños, eso sin contar las cuatro diputaciones obtenidas con su alianza con el Partido Verde Ecologista de México (PVEM). En las siguientes legislaturas, como se puede observar en la Gráfica 2, hubo pluralidad en el Congreso, pero esto no representó un contrapeso real para la trayectoria y equilibrio institucional de los agentes que controlan el poder político en Quintana Roo.

Una situación similar se ha presentado en los municipios en los cuales la oposición ha derrotado al PRI. Sin embargo, como se aprecia en el Cuadro 3, cuando el equilibrio institucional parece iniciar una nueva trayectoria, en realidad regresa al statu quo anterior. Este retorno del PRI podría explicarse como un buen síntoma de la vida democrática, aunque cada contexto es distinto en los Gobiernos subnacionales, sobre todo si se consideran la conformación y la trayectoria institucional a través de las cuales los enclaves autoritarios han tenido un efecto negativo sobre la democracia subnacional. El Cuadro 3 muestra la alternancia vivida en los municipios hasta antes de las elecciones de gobernador de 2016. 
Cuadro 3. Municipios de Quintana Roo con alternancia política ${ }^{3}$

\begin{tabular}{lcl} 
Municipio & Periodo & Partido político o coalición \\
Benito Juárez & $1975-2002$ & PRI \\
& $\mathbf{2 0 0 2 - 2 0 0 5}$ & PVEM \\
& $2005-2008$ & PRI \\
& $\mathbf{2 0 0 8 - 2 0 1 1}$ & PRD-PT-Convergencia \\
& $\mathbf{2 0 1 1 - 2 0 1 3}$ & PRD-PAN-PT-Convergencia \\
& $2013-2016$ & PRI-PVEM-PANAL \\
Cozumel & $1975-2005$ & PRI \\
& $\mathbf{2 0 0 5 - 2 0 0 8}$ & PAN-Convergencia \\
Isla Mujeres & $2008-2016$ & PRI \\
& $1975-2008$ & PRI \\
& $\mathbf{2 0 0 8 - 2 0 1 1}$ & PAN \\
& $\mathbf{2 0 1 1 - 2 0 1 3}$ & PAN \\
Lázaro Cárdenas & $2013-2016$ & PRI \\
& $1975-2011$ & PRI \\
& $\mathbf{2 0 1 1 - 2 0 1 3}$ & PAN-PRD-PT-Convergencia \\
José María Morelos & $2013-2016$ & PRI \\
& $1975-2011$ & PRI \\
& $\mathbf{2 0 1 1 - 2 0 1 3}$ & PRD \\
Felipe Carrillo & $2013-2016$ & PRI \\
Puerto & $1975-2005$ & PRI \\
& $\mathbf{2 0 0 5 - 2 0 0 8}$ & PRD \\
& $2008-2011$ & PRI \\
& $\mathbf{2 0 1 1 - 2 0 1 3}$ & PRD-PAN-PT-Convergencia \\
& $2013-2016$ & PRI \\
\hline
\end{tabular}

Fuente: elaboración propia con datos del IEQROO (2016b).

De lo anterior, se puede cuestionar el tipo de valores e instituciones que se han desarrollado en la ciudadanía y la oposición política en Quintana Roo, por el cual, a pesar de los cambios políticos, se termina regresando al statu quo controlado por el PRI. Este poco interés de la sociedad en los asuntos públicos y, sobre todo, en la oposición política es un reto que han afrontado los agentes que han bus-

3. La elección del periodo 201 I-2013 fue, por única ocasión, para dos años y cuatro meses de gobierno.

\section{8}


cado disputar el control político al PRI en el estado. Así lo señaló Israel Vera Rodríguez, el representante del partido Movimiento Ciudadano ante el consejo local del Instituto Nacional Electoral (INE) en Quintana Roo y ante el Consejo General del Instituto Electoral de Quintana Roo (IEQROO):

En Quintana Roo falta que la oposición logre ganar más adeptos con los ciudadanos que se abstienen de participar o en [con] quienes anulan su voto. De igual forma, la diversidad del electorado que proviene de muchos estados de la república hace más complejo el convencer con una plataforma electoral, que debe considerar todas las necesidades de los votantes. Los ciudadanos son fundamentales para romper con el voto clientelar o corporativo que mantiene a los partidos tradicionales. Lograr que vote un $25 \%$ más de la población es el gran reto de la oposición, y si se logra se pueden cambiar las tendencias de votación (entrevista personal, 2016).

En este mismo sentido, los cambios de Gobierno a nivel municipal quizá sean una decisión producto más de pragmatismo o de efecto coyuntural que del desarrollo de una cultura política de la sociedad quintanarroense, situación que también observan los empresarios:

[A] la población urbana no le interesa la política y vota por servicios, no por una cuestión ideológica [...] por tal motivo, no hay una sociedad civil activa que sea la causante de que se haya dado la alternancia en los municipios [...], esto lo menciono porque una sociedad civil organizada desarrolla valores y los valores se desarrollan con el tiempo. Tú lo puedes observar en ciudades viejas, como el Distrito Federal [Ciudad de México] o Guadalajara. En Quintana Roo, la élite política es poco preparada, por no decir ignorante [...], esto los ha llevado a implementar políticas de corte rural, como los subsidios, que a la larga hace[n] que la gente sea incompetente, conformista y dependiente (entrevista personal, 2015a). 
El poco desarrollo de una ciudadanía activa y de una oposición política robusta se puede explicar si se retoman los referentes teóricos que plantean que cuando un grupo de agentes controlan los Gobiernos subnacionales esto, generalmente, involucra el control territorial de la política, de la sociedad y sobre todo de la economía local.

De acuerdo con Gervasoni (2011), el control económico lleva a situaciones rentistas cuando los Gobiernos subnacionales reciben transferencias federales que difícilmente podrían conseguir por recaudación tributaria. En el caso de Quintana Roo, el control de la economía local es lo que ha ayudado a los agentes a retomar el control político cuando lo han perdido en las legislaturas y también en los municipios. El control de la economía local se ha llevado a cabo por medio de las transferencias de las participaciones y aportaciones federales, ${ }^{4}$ las cuales han aumentado de manera invariable debido en gran medida a la producción petrolera del país. En el siguiente cuadro, se observa que desde que se dio la alternancia democrática a nivel nacional, en el año 2000, los recursos no han dejado de fluir a Quintana Roo.

\section{Cuadro 4. Aportaciones y participaciones federales} en Quintana Roo (2000-2015)

\begin{tabular}{lccc} 
Ingresos & Año & Año & Incremento \\
& 2000 & 2015 & porcentual \\
Participaciones & 1810731014.00 & 8275981000.00 & $78 \%$ \\
federales & & & \\
Aportaciones federales & 2487227204.0013596045000 .00 & $82 \%$ \\
\hline
\end{tabular}

Fuente: elaboración propia con datos de INEGI (2016a).

4. Las participaciones federales se transfieren por medio del ramo 28 , que incluye los recursos asignados a los estados y los municipios en los términos establecidos por la Ley de Coordinación Fiscal y los convenios de adhesión al Sistema de Coordinación Fiscal y de Colaboración Administrativa en Materia Fiscal Federal. Las aportaciones federales, por su parte, se dan a través del ramo 33, el cual es el mecanismo presupuestario que permite fortalecer la capacidad de respuesta de los estados y municipios y atender demandas de gobierno en los rubros de educación, salud e infraestructura básica (SHCP, 2016). 
Es importante señalar que este panorama no es exclusivo de Quintana Roo, sino una constante en todos los Gobiernos subnacionales en México. De acuerdo al Instituto Mexicano para la Competitividad (IMCO), entre 1994 y 2014 los ingresos de los estados crecieron $220.2 \%$ en términos reales, de lo cual $201.2 \%$ se debió a transferencias federales y únicamente $4.2 \%$ a la generación de ingresos propios (Suárez, 2016). La consecuencia de este equilibrio imperfecto se relaciona directamente con la presencia de actores sociales menos autónomos y políticamente menos exigentes, en un panorama donde la subordinación es una regla informal que se ha osificado con el tiempo y ha contribuido a consolidar la trayectoria del equilibrio institucional controlado por el PRI.

Cabe señalar que aunque los ingresos por cobro de impuestos no son la principal fuente de recursos se han incrementado en un 89\% del año 2000 al 2016 (INEGI, $2016 b)$. No obstante, esto no ha representado una mejora en el desempeño gubernamental. Por ejemplo, la Encuesta Nacional de Calidad e Impacto Gubernamental (ENCIG) del 2015 mostró que el 43.6\% -lo que representa el penúltimo lugar de la escala de la ENCIG- de la sociedad en Quintana Roo está insatisfecha con los servicios públicos básicos y los servicios públicos bajo demanda, de manera específica, con el alumbrado público y su mantenimiento, parques y jardines públicos, seguridad y la falta de servicios médicos (IMSS e ISSSTE) (ENCIG, 2016).

La insatisfacción con el desempeño gubernamental ha sido una constante. El hecho de que los agentes en el Gobierno no hayan revertido la situación indica que dichos agentes no dependen de la ciudadanía activa ni de una clase empresarial sólida ni de los ingresos por recaudación tributaria. Es necesario señalar que este statu quo ha sido rentable para los que han controlado la política territorial en Quintana Roo, es decir, el diseño institucional resultó adecuado y útil en un momento determinado para un grupo 
de agentes, pero se convirtió en un impedimento para el desarrollo democrático de la sociedad, sobre todo por el clientelismo y la burocratización profundamente arraigada.

Cabe recordar que la lucha de los grupos locales fue por ser incorporados a la burocracia, lo cual en ese contexto específico fue rentable y necesario para fortalecer la administración pública local, pero con el tiempo esa institución informal significaría uno de los obstáculos para el desarrollo político y económico del estado, particularmente de la parte sur del territorio. Actualmente la entidad tiene un porcentaje de población ocupada en el Gobierno estatal (5.2\%) mayor al promedio nacional (4.0\%) (México ¿cómo vamos?, 2015a y 2015b). ${ }^{5}$

Esto ha generado una gran carga para el Estado debida a los agentes que apostaron en el pasado y en el presente por esta política de generación de empleo que ha ocasionado un incremento considerable de la deuda pública, sobre todo en las dos más recientes administraciones estatales. La administración del exgobernador Félix González Canto (2005-2011) dejó una deuda pública de MXN 13025 690.00, lo que ha significado un grave riesgo financiero para la hacienda local debido a que el monto acumulado de la deuda fue $204.23 \%$ superior a las participaciones que recibió del Gobierno federal (Tépach, 2015). Por su parte, en el Gobierno de Roberto Borge Angulo (2010-2015) la deuda pública registró un aumento, calculándose en un total de MXN 21000 millones, lo que representa un 278\% de su participación federal (Patiño, 2014).

La burocratización de los activos de la sociedad en la entidad se ha dado mediante la creación de un número creciente de dependencias de Gobierno, que generalmente 
repiten funciones entre sí, lo que ha resultado incosteable. ${ }^{6}$ En 2013, el gobernador del estado, Roberto Borge Angulo, anunció una "reingeniería administrativa" para adelgazar la nómina, que en el Gobierno estatal involucró el movimiento de 13000 burócratas. De acuerdo al Ejecutivo estatal, la medida buscó un ahorro de MXN 400000000 (Caballero, 2013). Las secretarías eliminadas fueron las de Planeación y Desarrollo Regional (SEPLADER) y Cultura, que se fusionaron con la de Hacienda, la cual cambió de nombre a Secretaría de Planeación y Finanzas. También desaparecieron los organismos descentralizados Comité de Planeación del Desarrollo del Estado (COPLADE), el Consejo Estatal de Población (COESPO), la Comisión de Energía (CENER), el Fondo para el Desarrollo Económico de Quintana Roo (FODEQROO), el Instituto Forestal de Quintana Roo (INFOQROO), la Comisión de Mejora Regulatoria, la Comisión para el Desarrollo de la Etnia Maya y Comunidades Indígenas de Quintana Roo y el Instituto de Fomento a la Vivienda y Regularización de la Propiedad (INFOVIR) (Capistrán y Hernández, 2013).

Al problema expuesto se suma la disminución del porcentaje de inversión pública en la entidad con respecto al gasto total: en 2009, la inversión fue del 13.2\% del gasto, y para 2014 disminuyó al 6.8\% (Redacción, 2016). Lo anterior ha impactado en la clase empresarial poco consolidada debido a que sus principales clientes generalmente son los Gobiernos estatal y municipal, situación que ha acentuado el cierre de organismos empresariales. Por ejemplo, en 2015 desapareció la representación en la entidad de la Cámara Nacional de la Industria de Restaurantes y Alimentos Con-

6. En diciembre de 2015 el gobernador Roberto Borge realizó un evento para los burócratas del estado donde fueron rifados un automóvil, diez motocicletas, pantallas, tablets y un bono de extraordinario por MXN I 2289600 , esto a pesar de su programa de reingeniería administrativa, iniciado en 2013 , mediante el cual, hasta el cierre de 2015, habían sido despedidos 4000 burócratas, la mayoría de Chetumal, la capital del estado (Camel, 20I5). 
dimentados (CANIRAC) debido a la disminución del número de afiliados al organismo, que cayó en un $40 \%$ respecto a 2014 (Ortíz, 2014). También han dejado de operar una serie de comercios de diversos giros (zapaterías, tiendas de ropa, abarrotes, entre otros) debido a la carga tributaria y al bajo poder adquisitivo de la población (Pat, 2014). Incluso la industria que fue representativa en la fundación institucional del estado, la forestal, hoy en día continúa con bajos niveles de rentabilidad. En el Cuadro 5 se puede observar que los municipios con mayor actividad forestal (Othón P. Blanco y Felipe Carrillo Puerto) presentan altibajos desde el año 2000 en esta actividad primaria.

Gráfica 3. Volumen de la producción maderable forestal (metros cúbicos rollo)

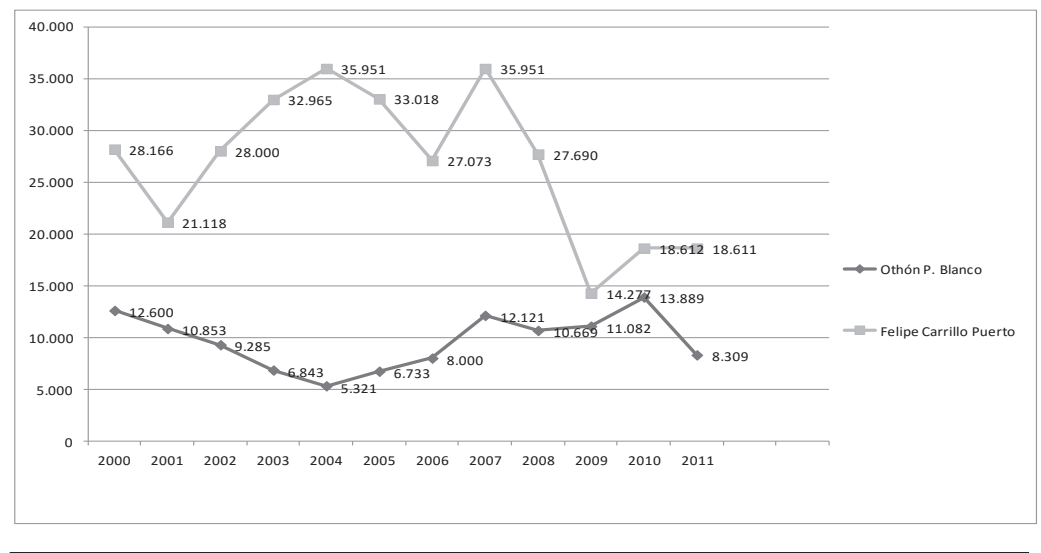

Fuente: elaboración propia con datos de INEGI (2016b).

Esta situación no se debe únicamente a una pérdida de riqueza forestal, sino a la falta de competitividad gubernamental, ya que los costos de las fallas burocráticas (falta de permisos, programas de manejos de recursos naturales y asesoría técnica) impactan significativamente. El presi- 
dente de la Coordinadora de Organizaciones Campesinas Forestales de Quintana Roo, Cristóbal Uc Medina, señala:

El estado de Quintana Roo tiene una vocación forestal desde hace años, pero los ejidos necesitan del apoyo de las autoridades, ya que, por ejemplo, si un ejido quiere certificarse a nivel internacional, tiene que cumplir con un proceso que a su vez exige lineamientos específicos, y es ahí donde nos pueden ayudar con algún recurso para que los núcleos agrarios logren validarse y con ello obtener el distintivo internacional (Rodríguez, 2015).

La falta de instituciones (leyes o reglas) no sólo se refleja en la carencia de una ciudadanía activa y una oposición política, sino también en el alto costo de la competitividad estatal, sobre todo en el sur del estado. ${ }^{7}$ Por ejemplo, el Índice de Competitividad Urbana 2016 (ICU2016) señala que el nivel de competitividad de la ciudad de Chetumal es bajo y se ubica en el lugar 71 de 74 ciudades evaluadas (IMCO, 2016).

En esa misma línea, el municipio de Othón P. Blanco tiene $42.9 \%$ de su población en situación de pobreza, Felipe Carrillo Puerto el 71.6\% y José María Morelos el 73.2\% (CONEVAL, 2015). Esto contrasta con lo que se vive en los municipios de Benito Juárez y Cozumel, donde los niveles de pobreza no superan el 32\% (CONEVAL, 2015).

7. La falta de competitividad en el sur también se da porque la clase empresarial no se ha renovado y muchos de los pequeños comerciantes y empresarios no se han modernizado con nuevas tecnologías que mejoren los servicios que ofrecen. Por ejemplo, en Chetumal muchos empresarios desconocen lo que implica la reforma hacendaria. Joaquín Ismael Noh Mayo, presidente de la Unión de Propietarios de Restaurantes, Bares y Similares, señala: "Algunos propietarios tienen sesenta $\circ$ sesenta y cinco años de edad. Hay hasta más grandes, y están pensando cerrar, rentar o traspasar sus negocios porque no conocen bien los cambios que trajo la reforma [hacendaria] para estos negocios. Porque tampoco hay recursos para equiparse y hacer la facturación electrónica. Ellos ya no tienen paciencia para llevar una contabilidad sobre sus gastos e ingresos $y$ hay algunos que no saben leer y escribir bien" (Martín, 20l4). 
Estos dos últimos municipios se encuentran en el norte del estado, donde la industria de turismo masivo ha tenido un crecimiento sostenido desde la década de 1960, cuando se empezó a apostar por un modelo de desarrollo alejado de las actividades forestales, propias del sur de la entidad. Entre 2012 y 2014 llegaron al estado 28189730 turistas, la mayoría a Cancún, Cozumel y la Riviera Maya, quienes dejaron una derrama económica de USD 22000626.26 (SECTUR, 2015). En el Cuadro 6 se aprecia que la disponibilidad de cuartos de hotel en el norte del estado contrasta con la disponibilidad de cuartos de hotel del centro y sur de la entidad:

Cuadro 5. Cuartos y unidades de hospedaje registrados por municipio y categoría (2013)

\begin{tabular}{lrrrrrrr} 
Municipio & Total & $\begin{array}{c}\text { Cinco } \\
\text { estrellas }\end{array}$ & $\begin{array}{c}\text { Cuatro } \\
\text { estrellas }\end{array}$ & $\begin{array}{c}\text { Tres } \\
\text { estrellas }\end{array}$ & $\begin{array}{c}\text { Dos } \\
\text { estrellas }\end{array}$ & $\begin{array}{c}\text { Una } \\
\text { estrella }\end{array}$ & $\begin{array}{c}\text { Sin } \\
\text { categoría }\end{array}$ \\
Benito Juárez & 35680 & 27422 & 4780 & 2563 & 509 & 371 & 35 \\
Cozumel & 4098 & 1776 & 1641 & 350 & 232 & 83 & 16 \\
Isla Mujeres & 2080 & 995 & 188 & 250 & 176 & 136 & 335 \\
Solidaridad & 34671 & 28828 & 2861 & 1345 & 408 & 16 & 1213 \\
Tulum & 6237 & 3864 & 364 & 297 & 58 & 34 & 1620 \\
Lázaro & 710 & 0 & 112 & 116 & 30 & 80 & 372 \\
Cárdenas & & & & & & & \\
Felipe & 160 & 0 & 0 & 83 & 47 & 5 & 25 \\
Carrillo & & & & & & & \\
Puerto & & & & & & & \\
José María & 90 & 0 & 0 & 0 & 28 & 45 & 17 \\
Morelos & & & & & & & \\
Bacalar & 263 & 0 & 0 & 85 & 40 & 70 & 68 \\
Othón P. & 2599 & 557 & 152 & 811 & 488 & 332 & 259 \\
Blanco & & & & & & & \\
\hline
\end{tabular}

Fuente: elaboración propia con datos de INEGI (2014).

Esta industria del turismo masivo es lo que ha hecho de Cancún (municipio de Benito Juárez) una ciudad competi- 
tiva de acuerdo al ICU2016, que la ubica en el lugar 13 de la lista de 74 ciudades (IMCO, 2016). Asimismo, se podría afirmar que el peso de la industria turística en la zona norte, aunado a la competitividad de su principal ciudad, ha sido determinante para la formación de valores democráticos que expliquen la alternancia política vivida en el municipio de Benito Juárez en 2002.

Asumir esta postura significa estar en la misma sintonía de los argumentos de los clásicos del estudio del cambio político: Dahl (1993), Linz (1994), Huntington (1994), Morlino (1985) y O’Donnell y Schmitter (1998), quienes plantean que las transiciones políticas en parte se dan porque la sociedad alcanza grandes niveles de educación y urbanización, se incrementa la clase media, se desarrollan nuevos valores con la democracia o existen conflictos y fracturas del régimen político que implican el arribo de oposición política -que disputa un cambio en las reglas del equilibrio institucional imperante-. No obstante, en contextos más acotados como en los Gobiernos subnacionales y sus municipios, las características teóricas mencionadas no suelen encajar de manera simétrica, sobre todo porque la alternancia o el cambio de equilibrio institucional en la mayoría de los municipios mencionados retornó al statu quo antecesor (véase: Cuadro 3).

Más bien, la alternancia municipal en Quintana Roo se puede explicar desde los planteamientos del nuevo institucionalismo, según el cual los conflictos para generar un cambio se pueden dar desde el interior de la misma organización que posee el control de las reglas, es decir, no son necesarios la formación de una oposición o élite política ni el desarrollo de una clase media o sociedad civil. En Quintana Roo, sin embargo, el conflicto político se ha presentado entre agentes inconformes que han renunciado al PRI y se han afiliado a otro partido, sin que esto signifique el desarrollo de una verdadera oposición. Tres ejemplos: 1) en la elección 
municipal del 2010 en Felipe Carrillo Puerto, Sebastián Uc Yam renunció al PRI y se incorporó al PRD para ganar la alcaldía; 2) en la elección de 2005 en Cozumel, el candidato Gustavo Ortega Joaquín, militante priista de 1990 al año de la elección, renunció al PRI y se afilió al PAN para ganar la alcaldía; 3) en la misma elección de 2005, pero para aspirar al cargo de gobernador, Addy Joaquín Coldwell renunció al PRI para contender por el PAN y Convergencia (Chávez, 2005).

\section{Nacionalización del conflicto y cambio del equilibrio institucional en Quintana Roo}

Lo expuesto no ha implicado el desarrollo de valores democráticos en la ciudadanía quintanarroense y sí una diversificación del control de los grupos que se disputan el poder político en el estado, situación que explica la alternancia vivida en la elección de gobernador de 2016, en la cual el candidato de la coalición del PAN-PRD, Carlos Joaquín González, derrotó al PRI por primera vez en cuarenta y dos años.

La explicación del cambio político en la gubernatura está en los referentes teóricos y en los sucesos vividos en las alternancias municipales del estado, es decir, en el conflicto político al interior del partido dominante y de sus grupos, aunque en el caso de la gubernatura se puntualizó el conflicto entre las familias Borge-González y Joaquín, integrantes de una élite política más definida y que facilitó a los grupos llevar a lo nacional los conflictos locales.

Aunque esta élite (de gran influencia política y económica) ha protagonizado los conflictos de mayor impacto por el control de las instituciones del estado, estos no han significado que la trayectoria de la política dominante se modifique, ya que el PRI siguió controlando la gubernatura del estado; es decir, la élite (Borge-González y Joaquín), más allá de 
la lucha por el control político, siempre logró negociar la rentabilidad de la persistencia del equilibrio institucional, esto es, que el PRI como partido mantuviera la gubernatura. No obstante, desde 1999 la lucha por la gubernatura entre las familias de la élite ha sido constante. ${ }^{8}$ Su disputa por el control institucional ocasionó que la posibilidad de un nuevo equilibrio político fuera rentable.

Tal como plantean los aportes de la teoría de la democracia subnacional, una vía para alcanzar esto fue identificar una crisis local en la cual la oposición elevó el conflicto local a los actores nacionales y articuló el conflicto con los intereses políticos o territoriales de dichos actores. En la ciudadanía quintanarroense fue patente el descontento por la toma de decisiones de los agentes que controlaban el Gobierno estatal, no sólo el malestar por la calidad de los servicios básicos, sino también por los recortes y eliminación de puestos de trabajo en la burocracia estatal y municipal.

A esto se sumó la impunidad y la corrupción de los actores políticos encabezados por el exgobernador Roberto

8. Se mencionan dos conflictos entre grupos de agentes al interior del PRI. I) El primer enfrentamiento directo entre los Borge-González y los Joaquín ocurrió durante el proceso de sucesión del gobernador Mario Villanueva, en 1999. El prospecto deVillanueva era el chetumaleño Jorge Polanco Zapata, en ese entonces senador, mientras que el presidente Ernesto Zedillo respaldaba a Addy Joaquín Coldwell, hermana mayor de Pedro Joaquín. En medio de su enfrentamiento con el presidente por la sucesión, Mario Villanueva fue acusado penalmente de vínculos con el narcotráfico, mientras que Jorge Polanco, su delfin, fue señalado en columnas políticas de participar en actividades ilícitas; también en aquella ocasión, el PRI optó por una elección interna en la que participaron Addy Joaquín, apoyada por su hermano,y el chetumaleño Joaquín Hendricks, que fue procurador y diputado federal, apoyado por Miguel Borge. En una cuestionada elección interna, Hendricks se convirtió, con el apoyo de Mario Villanueva, en el candidato del PRI y después en gobernador (1999-2005). Tras la nominación de Hendricks, un año después, en 2000, Addy fue senadora por el PRI. 2) En 2010, el entonces gobernador Félix González Canto impuso como candidato a Roberto Borge Angulo frente a Carlos Joaquín González, quien era diputado federal. Aunque Joaquín amagó con irse al PAN, aceptó la nominación de Borge, pero a cambio obtuvo para su gente las candidaturas a las alcaldías de Playa del Carmen, Tulum y Cancún, aunque en la elección constitucional de este último municipio repitió triunfo el PRD (Caballero, 20I6). 
Borge Angulo. Por ejemplo, la ENCIG reveló que en 2015 la prevalencia de corrupción en la entidad fue mayor a la registrada a nivel nacional (13 085 vs. 12590 por cada 100000 habitantes, respectivamente) (ENCIG, 2016), esto aunado a la existencia de altos niveles de endeudamiento público no reflejados en una mejora en la calidad de vida de los habitantes.

No obstante, a nivel estatal, al igual que sucedió recientemente en las elecciones municipales, el conflicto de la élite al interior del PRI fue lo que realmente configuró la fractura del equilibrio imperante. En las elecciones para la gubernatura, en 2016, el exgobernador Roberto Borge buscaba imponer a su sucesor (José Luis Toledo Medina) y evitar que Carlos Joaquín Coldwell, el entonces subsecretario de Turismo y hermano del secretario de Energía, Pedro Joaquín Coldwell, tuviera posibilidades de competir por la nominación priista. El conflicto fue llevado por los actores inmersos a la dirigencia nacional, la cual definió que el candidato del PRI sería el alcalde del municipio de Solidaridad, Mauricio Góngora Escalante. Al quedar excluido del arreglo, Carlos Joaquín renunció a la militancia priista y se convirtió en candidato de la alianza PAN-PRD (Caballero, 2016).

La renuncia de Carlos Joaquín al PRI no disminuyó los incentivos del exgobernador Roberto Borge para actuar de manera furtiva. Borge buscó boicotear la campaña del candidato de la alianza PAN-PRD (Varillas, 2016a; Noticaribe, 2016). ${ }^{9}$ Este tipo de prácticas, que como señalan los referen-

9. Por ejemplo, el 16 de noviembre de 2015 se localizó una bodega con cajas de despensa y propaganda del entonces alcalde del municipio de Solidaridad, mientras que se supo que para el festejo del Grito de Independencia de ese año, el 16 de septiembre, el edil contrató al grupo musical Los Tigres del Norte, quienes cobran USD 300000.00 por presentación (Caballero, 2016). De igual forma, durante la campaña, los eventos de la alianza PAN-PRD fueron boicoteados por actores políticos afines al PRI, por ejemplo, en Bacalar, Chetumal y Cancún, los eventos fueron clausurados por supuestamente no contar con medidas de seguridad o fueron infiltrados por el programa Basura por Alimentos, del Gobierno estatal (Noticaribe, 2016). 
tes teóricos son difíciles de medir pero tienen un impacto sobre la política, fueron las que caracterizaron la campaña electoral en el estado. No obstante, la nacionalización del descontento ciudadano por parte de los partidos de oposición fue lo que llevó a que ganara la elección el candidato Carlos Joaquín González por una ventaja de once puntos porcentuales (Pacheco y Vázquez, 2016; Varillas, 2016a).

Con la victoria electoral de la alianza PAN-PRD, el cambio político y de statu quo de manera formal estaba dado por primera vez en la historia de Quintana Roo. No obstante, es importante considerar el alcance de este cambio y, sobre todo, si la path dependence que se ha mantenido desde la fundación del estado podrá ser cambiada por un nuevo equilibrio institucional. Lo anterior se menciona debido a que, al igual que ha sucedido en los municipios del estado, la posible persistencia del equilibrio institucional en la gubernatura del estado de Quintana Roo involucra una serie de instituciones arraigadas (rutinas, normas y acuerdos) que podrían dificultar un cambio de trayectoria institucional.

Es importante considerar que no se tiene una oposición política desarrollada en el estado, y que el candidato ganador de la señalada elección, Carlos Joaquín González, perteneció al PRI y sigue formando parte de la élite política y económica que ha influido en la trayectoria institucional del estado desde su creación. En este mismo sentido, el desempeño de la oposición política ha tenido altibajos y una trayectoria complicada por definir debido al poder que han ejercido los gobernadores sobre todos los agentes políticos en la entidad:

La oposición en primera instancia debe ser sólida y con principios [...]; cuando tenemos políticos con principios podemos hablar de un buen cambio de rumbo, sin importar si [el político con principios] es del PAN, del PRD o del PRI. El tema es que si nuestra oposición no se fortalece de manera íntegra, donde [sic] no se dejen comprar, donde [no] se dejen 
inmiscuir en estos temas de corrupción, pues obviamente [no] vamos a tener una oposición fortalecida (entrevista personal, 20l5b).

Lo anterior se señala debido a que la oposición en el estado no se ha fortalecido como una opción competitiva ante el equilibrio institucional representado por el PRI. En las elecciones de 2010, en las que se eligieron gobernadores y alcaldes, la oposición, formando alianzas de partidos políticos (PAN, PRD, PT, Convergencia), ganó más elecciones municipales (cinco municipios). Sin embargo, esta fue una victoria coyuntural -al igual que la de la elección de 2016-, en la que la figura carismática de Gregorio Sánchez Martínez, el candidato a gobernador de la alianza opositora (PRD-PT-Convergencia), influyó de manera determinante (aunque su arresto por acusaciones de nexos con el crimen organizado eliminó la posibilidad de una posible victoria) (Martoccia, 2010). ${ }^{10}$

En este complejo escenario sociopolítico, en el que, como se vio en la elección de 2016, se pondera más a la persona que al partido, es donde toman relevancia los valores, normas y acuerdos arraigados en las instituciones clientelares, los cuales se han osificado en la sociedad y dificultan el cambio institucional. Por ejemplo, la misma sociedad se resiste a desburocratizar su relación clientelar con el Gobierno, esto debido a que ellos votaron por el cambio en el mismo y no por una política de recortes de la nómina estatal, situación que en el caso de Quintana Roo resulta inevitable si se considera la deuda pública del estado.

Cabe señalar que una de las políticas que persiguió el movimiento nativista desde la creación del estado fue que la sociedad formara parte de la administración pública, regla

10. La Comisión Política Nacional del PRD nombró a Gerardo Mora Vallejo, coordinador general de campaña, como candidato sustituto a la gubernatura y representante de la alianza Todos por Quintana Roo (PRD-PT-Convergencia) (CNN México, 20I0). 
informal que se institucionalizó y se osificó con el tiempo, con consecuencias para la competitividad de la sociedad: ${ }^{11}$

Existe mucha dependencia entre Gobierno y sociedad, o más bien codependencia [...]; iqué herramientas les damos a nuestros empresarios? [...] poco han logrado porque hay pocas condiciones de inversión, y no porque no haya condiciones para la inversión [en] el sur del estado, pero se ha concentrado no en el servicio, [sino] se ha concentrado en el Gobierno en el esquema burocrático,y no le hemos dado alternativas al inversionista para que venga a invertir [...], porque nadie va a venir a invertir para perder su dinero. Una clase empresarial sólida permite que la democracia tenga esos esquemas de negociación, porque ahorita las condiciones hacen que el norte tenga un peso político inmenso y nuestra clase empresarial del sur está [en] total desventaja (entrevista personal, 20I5b).

Sobre esta misma línea, se analiza y se critica la situación en el centro y sur del estado, involucrando aspectos de los valores arraigados que han dado origen a parte de la idiosincrasia de la sociedad del sur respecto al norte del estado, en el cual se puede ubicar a la única élite política y económica de la entidad:

[...] es una sociedad rural [...], las élites también son rurales, y cuando digo rurales no me refiero necesariamente a campesinos, sino que su pensamiento, su estructura de organizarse está [fundamentada] mucho en valores rurales. ¿Qué son esos valores rurales? El patrimonialismo, las prebendas, la cultura de los favores. Si tú tienes una cultura de

I I. Esta falta de valores e instituciones que incentiven la productividad también se aprecia en los activos que forman las universidades de la entidad. Ocho de cada diez egresados de la carrera de Seguridad Pública, impartida en la Universidad de Quintana Roo campus Chetumal, son rechazados por no aprobar los exámenes de control y confianza. De acuerdo al secretario de Seguridad Pública del estado, Juan Pedro Mercader Rodríguez, los jóvenes reprueban porque no quieren ser policías, es decir, no escogen la carrera por vocación y convicción, sino porque buscan sólo tener un empleo seguro al finalizar la carrera universitaria (Moguel, 2016). 
favores, [esto] afecta los impuestos, porque todo se vuelve un favor. En esta ciudad [Chetumal] todo se vuelve un favor [...]; cuando tienes una sociedad, tanto ciudadanos como gobernantes, con características fuertemente patrimonialistas [...] [esto] no puede ser, y eso no sólo está ligado a la pobreza, sino a la manera de pensar. El hecho de que Chetumal sea la capital del estado,y que sólo se viva de la burocracia [en ella], eso en sí mismo es un problema, [...] porque el único municipio donde se hacía el doble de trámites era este [Othón P. Blanco]. Había que hacer trámites ante el Ayuntamiento y ante el Gobierno del estado porque el municipio necesita[ba] justificar su trabajo [...]; el problema de Chetumal es que está para rendir culto al gobernante, a pesar de que hay baches, a pesar de que hay oposición [...]. [Si en la ciudad que gobiernas tienes esta situación], lo que estás haciendo es desincentivar que se asienten las empresas [en tu ciudad] [...]. [Además] la gente tampoco tiene una cultura del trabajo, es un Gobierno caro por su ineficiencia burocrática, es caro porque genera costos internos, [por ejemplo] en mi negocio, porque no me da la gente para que yo pueda trabajar, se reduce la competitividad (entrevista personal, 20I5a).

Es importante mencionar que a pesar de que el norte del estado es más competitivo económicamente hablando, no está exento de las mismas prácticas patrimonialistas y clientelares que se observan en el centro y sur del estado. ${ }^{12}$ Esto en sí representa un riesgo para que el cambio político se consolide, aunque dependerá de la legitimidad de las decisiones que los actores políticos tomen y sobre todo la rapidez con que los resultados sean observados empíricamente y comunicados por el Gobierno.

12. En 2016, la Fiscalía Especializada para la Atención de Delitos Electorales (FEPADE) giró trescientas órdenes de aprehensión para castigar el turismo electoral que se dio de Yucatán a Quintana Roo para favorecer la campaña y votación del entonces candidato a gobernador, Roberto Borge Angulo (Varillas, 20I6b). 


\section{Conclusión}

En el presente artículo se analizó el diseño del origen institucional del estado de Quintana Roo, el cual definió la trayectoria sobre la que se ha conducido la política en la entidad. Asimismo, se estudiaron, desde los referentes del nuevo institucionalismo y de la democracia subnacional, los factores que han incidido en la formación de una trayectoria que hasta la elección de 2016 impidió que se diera un cambio político. No obstante, dado el triunfo de la alianza opositora conformada por el PAN-PRD en la entidad, se planteó en el presente trabajo una hipótesis: las razones que condujeron al cambio político en el Gobierno de Quintana Roo no son variables determinantes para que un nuevo régimen consolide el cambio institucional del estado y su sociedad. Lo anterior se debe al diseño institucional de origen, el cual se manifiesta en una sociedad burocratizada y dependiente de los agentes del Gobierno.

Se argumentó que el costo de formar este tipo de reglas es el de los bajos niveles de democracia, costo en el que el esquema federalista ha jugado un papel determinante. Esto quiere decir que los actores sociales son menos autónomos y políticamente menos exigentes cuando el Gobierno subnacional domina la economía local. Por tal motivo, uno de los grandes problemas de la democracia en México está en la permanente búsqueda de su consolidación a nivel nacional mientras se ha dejado de lado a los Gobiernos subnacionales, que no han podido ser disciplinados en su transición a la democracia. Cuando estos Gobiernos han experimentado la alternancia democrática, generalmente se han encontrado con que para gobernar requieren instituciones formales cuya operación no necesariamente se adapta a un sistema en el que la discrecionalidad en la toma de decisiones es una conducta osificada en el Gobierno y en la sociedad. 
En este punto, se destacó la importancia de los cambios institucionales, en tanto son a los que los agentes recurren cuando el orden establecido deja de ser benéfico para la mayoría o para aquellos que disputan el poder político. Esto significa combatir una serie de reglas contra las que diversos agentes opondrán una resistencia natural, incluso aquellos que creyeron que con un cambio de reglas podrían estar mejor que en el equilibrio anterior.

Ahora bien, en la resistencia natural a los cambios institucionales también participa el Gobierno como jugador activo. Desde la racionalidad, puede apostar por cambiar una serie de instituciones, sin que esto signifique cambiar la trayectoria institucional histórica -en la que la sociedad ha sido dependiente del Gobierno en turno-.

De ahí la necesidad de fortalecer la democracia subnacional por medio de mejores procesos de participación ciudadana. El desarrollo y consolidación de la ciudadanía debe dejar de personalizar la política, es decir, votar por las plataformas electorales y no necesariamente por la imagen del candidato. Este reto conlleva tener una clase política profesionalizada, una élite empresarial autónoma del poder político y, sobre todo, una sociedad activa y participativa en cada una de las decisiones de su Gobierno, algo que en Quintana Roo parece haber iniciado, al menos en el terreno político, pero que como todo cambio institucional debe incrementarse. Además, se debe tener presente que es más fácil tomar decisiones cuando la sociedad tiene osificados los valores implícitos de las reglas del juego que cuando estas son nuevas y buscan cambiar la costumbre, en la que se encuentran las reglas informales, de una sociedad.

Bibliografía

\section{6}


https://www.jstor.org/stable/pdf/404208I I.pdf?refreqid Bibliografía =excelsior\%3Ab90d0 I c I 45e I fb6e83 I I cb625267422a Alcántara, M. (1992). "Las transiciones a la democracia en España, América Latina y Europa Oriental. Elementos de aproximación a un estudio comparativo". Revista del Centro de Estudios Constitucionales, I I, 9-42.

Arellano, A. (20I4a). "La coordinación metropolitana en el ámbito subnacional mexicano: un análisis institucional”. Documentos y Aportes en Administración Pública y Gestión Estatal, I4(23), 33-70. Recuperado de: http://www. redalyc.org/pdf/3375/337539/89002.pdf

(20 I4b).“"La definición jurídica del fenómeno metropolitano en el ámbito subnacional mexicano”. Opinión Jurídica, I3(26), 91-108. Recuperado de: http://revistas. udem.edu.co/index.php/opinion/article/view/958/I0 I I Aziz Nassif, A. (2003). "Estudio introductorio", en A. Aziz Nassif (coord.), México al inicio del siglo XXI. Democracia, ciudadanía y desarrollo (pp. 5-2I). México: Miguel Ángel Porrúa.

__ y Alonso Sánchez, J. (2003)."Los poderes y las instituciones”, en A. Aziz Nassif (coord.), México al inicio del siglo XXI. Democracia, ciudadanía y desarrollo (pp. 27-38). México: Miguel Ángel Porrúa.

Caballero, S. (0I de octubre de 20I3).“Comienzan despidos de burócratas en Quintana Roo: echan a cien”. Proceso. Recuperado de: http://www.proceso.com.mx/3542 I3/ comienzan-despidos-de-burocratas-en-quintana-

(04 de enero de 2016).“Quintana Roo:la disputa por la gubernatura... entre priistas”. Proceso. Recuperado de: http://www.proceso.com.mx/?p=425242

Camal, T. (2013). ¿Quién gobierna Quintana Roo? Estudio de una élite política local. México: Bonilla Artigas Editores.

Camel, A. (I 7 de diciembre de 2015).“Borge el 'espléndido': en el último diciembre Borge, de posada en posada, continúa derroche de regalos, ahora con burócratas". 
Bibliografía

Noticaribe. Recuperado de: http://noticaribe.zonalibredebelice.com/borge-el-esplendido-en-el-ultimodiciembre-de-borge-de-posada-en-posada-continua-derrochede-regalos-ahora-con-burocratas/

Campos, S. (20I2). "Paradojas de la transición democrática: autoritarismo subnacional en México". Estudios Políticos, (27), 2 I-45. Recuperado de: http://www.revistas.unam. mx/index.php/rep/article/view/33096/30308

Capistrán, O., y Hernández, F. (26 de agosto de 2013). “Severas medidas de austeridad". Por esto Quintana Roo. Recuperado de:http://www.poresto.net/ver_nota.php? zona $=$ qroo\&idSeccion $=3 \&$ idTitulo $=264790$

Careaga, L., e Higuera,A. (20I I). Historia breve. Quintana Roo. México: Fondo de Cultura Económica.

Casar, M. A. (0I de mayo de 1989). "Corporativismo y transición”. Nexos. Recuperado de: http://www.nexos. com.mx/?p=5443

Chávez, J. (22 de enero de 2005). “Dividida en coaliciones, la oposición aún espera derrotar al PRI en QR". La Jornada. Recuperado de: http://www.jornada.unam. $\mathrm{mx} / 2005 / 0 \mathrm{I} / 22 / 035 \mathrm{n}$ l est.php

CNN México (I 4 de junio de 20 I0).“El PRD designa a Gerardo Mora en sustitución de Greg”. Expansión. Recuperado de: http://expansion.mx/nacional/20 I0/06/ /4/el-prddesigna-a-gerardo-mora-en-sustitucion-de-greg

CONEVAL ( 16 de diciembre de 2015). "Medición de la pobreza en México 2010, a escala municipal”. Consejo Nacional de Evaluación de la Política de Desarrollo Social. Recuperado de: http://www.coneval.gob.mx/Medicion/ MP/Paginas/Medicion-de-

Congreso del Estado de Quintana Roo (2016).“'Legislaturas anteriores”. Poder Legislativo del Estado de Quintana Roo. Recuperado de: http://www.congresoqroo.gob.mx/ legislaturas_anteriores/ 
Dahl, R. (1993). La poliarquía. Participación y oposición. México: Bibliografía REI.

ENCIG (2016). "Encuesta Nacional de Calidad e Impacto Gubernamental”. Instituto Nacional de Estadística y Geografia. Recuperado de: http://www.inegi.org.mx/est/ contenidos/proyectos/encuestas/hogares/especiales/ encig/20I5/doc/encigl5_principales_resultados.pdf

Evans, P., Rueschemeyer, D., y Skoopol,T. (1979). Bringing the state back in. Cambridge: Cambridge University Press.

Gervasoni, C.(20I I).“Una teoría rentística de los regímenes subnacionales: federalismo fiscal, democracia y autoritarismo en las provincias argentinas". Desarrollo Económico, 50(200), 579-6I0.

Gibson, E. L. (2007). “Control de límites: autoritarismo subnacional en países democráticos”. Desarrollo Económico, 47(186), 163-191.

Gobierno del estado de Quintana Roo (20I5)."Historia del estado de Quintana Roo”. Recuperado de: http://www. quintanaroo.gob.mx/qroo/Estado/Historia.php

Hall, P., y Taylor C. R. (1996)." Political Science and the Three New Institutionalism”. Political Studies, XLIV, 936-957.

Hernández, G. (22 de diciembre de 2015a). Entrevista personal a empresario de Chetumal. Chetumal, Quintana Roo. (28 de diciembre de 20I5b). Entrevista personal a empresario chetumaleño. Chetumal, Quintana Roo. (18 de enero de 2016). Entrevista personal realizada a Israel Vera Rodríguez, representante del partido Movimiento Ciudadano ante el consejo local del Instituto Nacional Electoral (INE) en Quintana Roo y ante el Consejo General del Instituto Electoral de Quintana Roo (IEQROO). Playa del Carmen, Quintana Roo.

Huntington, S.(1991).“How countries democratize”. Political Science Quarterly, I06(4), 579-6I6. ( (1994). La tercera ola. La democratización a finales del siglo XX. Argentina: Paidós. 
Bibliografía
Ibarra, J., Sandoval, A., y Sotres, L. (200I). "Participaciones federales y dependencia de los gobiernos municipales en México, 1975-1995”. Investigación Económica, 6 I (237), 25-62.

IEQROO (03 de enero de 20 I 6a)."Estadística electoral gobernador, ayuntamientos y diputados". Instituto Electoral de Quintana Roo. Recuperado de http://www.ieqroo.org. $\mathrm{mx} / \mathrm{web} /$ index.php

(05 de enero de 2016b). "Histórico de resultados electorales Quintana Roo”. Instituto Electoral de Quintana Roo. Recuperado de http://www.ieqroo.org.mx/estadisticas_elec/eleccion I0/Ayuntamientos.html IMCO (2016). “Índice de Competitividad Urbana 2016 (ICU)”. Instituto Mexicano para la Competitividad. Recuperado de: http://imco.org.mx/competitividad/indice-de-competitividad-urbana-2016/

INEGI (20I4). Anuario estadístico y geográfico de Quintana Roo. México: Instituto Nacional de Estadística, Geografía e Informática.

- (24 de diciembre de 20I6a). "Estadística de finanzas públicas estatales y municipales”. Instituto Nacional de Estadística, Geografía e Informática. Recuperado de: http://www.inegi.org.mx/sistemas/mexicocifras/default. aspx? $=23$

(20 de diciembre de 2016b). "México en cifras, Quintana Roo". Instituto Nacional de Estadística, Geografia e Informática. Recuperado de http://www.beta.inegi.org. $\mathrm{mx} /$ app/areasgeograficas/\#

Linz,J. ( 1994). El factor tiempo en las transiciones democráticas. México: Centro de Estudios sobre la Transición.

Loaeza, S. (1994). "La experiencia mexicana de liberalización”. Foro Internacional, XXXIV(3), 22I-25I.

Macías, R. C. (1997). Nueva frontera mexicana. Milicia, burocracia y ocupación militar. México: Colección Sociedad 
y Cultura de la Vida de Quintana Roo, Universidad de Quintana Roo, CONACYT.

Martín, C. (I 2 de enero de 20 I4).“Empresarios sexagenarios ven en la reforma hacendaria una amenaza". Novedades de Quintana Roo. Recuperado de: http://sipse.com/ novedades/empresarios-chetumal-ignoran-reformahacendaria-

Martoccia, H. (26 de mayo de 20I6)." Detienen en Quintana Roo a Gregorio Sánchez, candidato al Gobierno del estado". La Jornada. Recuperado de: http://www.jornada. unam.mx/2010/05/26/politica/0I5n I pol

Merino, M. (2003). La transición votada. Crítica a la interpretación del cambio político en México. México: Fondo de Cultura Económica.

México ¿cómo vamos? (2015a)."Semáforo estatal Quintana Roo". Recuperado de: http://mexicocomovamos.mx/ index.php?s=mcv_ei\&e $=23$

— (20I5b). "Semáforo económico". Recuperado de: http://www.mexicocomovamos.mx/

Moe,T.(1990)."Political institutions:The neglected side of the story”. Journal of Law, Economics, \& Organization, 6(abril, special issue), 213-253.

Moguel, A. (2016). "Fracasa carrera en Seguridad de la UQROO”. Política Quintana Roo. Recuperado de: http:// www.politicaqr.com/grillos-en-su-tinta/fracasa-carreraen-seguridad-de-la-

Morlino, L. (1985). Cómo cambian los regímenes políticos. Madrid: Centro de Estudios Constitucionales.

- (2005). Democracias y democratizaciones. México: Centro de Estudios de Política Comparada, A. C.

North, D. (1993). Instituciones, cambio institucional y desempeño económico. México: Fondo de Cultura Económica.

Noticaribe (I5 de abril de 2016). "Denuncia guerra sucia contra Carlos Joaquín: destruyen propaganda y agreden a colaboradores del candidato a la gubernatura por 
Bibliografía la alianza PAN-PRD”. Recuperado de: http://noticaribe. com.mx/2016/04/I5/denuncian-guerra-sucia-contracarlos-joaquin-destruyen-propaganda-y-agreden-acolaboradores-del-candidato-a-la-gubernatura-por-laalianza-pan-prd-en-qr/comment-page-I/

O'Donnell, G., y Schmitter, P. (1986). Transitions from Authoritarian Rule. Tentative Conclusions about Uncertain Democracies. Baltimore-Londres:John Hopkins University Press. - (1998). Transiciones desde un Gobierno autoritario. Conclusiones tentativas sobre las democracias inciertas. Argentina: Paidós.

Ortíz, A. (22 de mayo de 20l4). "Desaparece Canirac, oficinas centrales toman decisión al agrupar únicamente 15 restaurantes". Diario de Quintana Roo. Recuperado de: http://www.dqr.com.mx/index.php/sections/othonp-nirac

Pacheco, R.,yVázquez, F.(2016).“Aventaja Carlos Joaquín en Quintana Roo”. Excélsior. Recuperado de: http://www. excelsior.com.mx/nacional/2016/06/06/I097/24

Pat, B. (20 de mayo de 20I4). "La Canirac registra una disminución en números de negocios". Novedades de Quintana Roo. Recuperado de: http://sipse.com/novedades/ reduce-un-25-por-ciento-el-numero-de-afiliaciones-

Patiño, D. (I8 de noviembre de 2014). "Chihuahua y Quintana Roo, con las mayores deudas”. El Financiero. Recuperado de: http://www.elfinanciero.com.mx/economia/ chihuahua-y-quintana-roo-los-de-mas-deuda.html

Periódico Oficial del Estado de Quintana Roo (0I de enero de 2016). Recuperado de: http://po.qroo.gob.mx/portal/ Publicacion.php? Idcacion $=4737$

Peters, G. (2003). El nuevo institucionalismo. La teoría institucional en la ciencia política. Barcelona: Gedisa.

Pierre, J., y King, S. (2005). "The Politics of Path Dependence: Political Conflict in Historical Institutionalism". The Journal of Politics, 67(4), I275- I 300. 
Redacción (23 de mayo de 20I4).“Familia Joaquín Coldwell: Bibliografía emporio de política y comercio". El Universal-Unión Cancún Quintana Roo. Recuperado de:http://www.unioncancun.mx/articulo/20 I 4/05/23/gente/familia-joaquincoldwell-emporio-de-politica-y-comercio (I7 de mayo de 2016). “Baja en inversión pública y cuarto lugar en corrupción, balance de Quintana Roo rumbo a las elecciones". Animal Político. Recuperado de: http://www.animalpolitico.com/2016/05/baja-eninversion-publica-y-cuarto-lugar-en-corrupcion-balancede-qroo-rumbo-a-elecciones/

Rodríguez, E. (06 de junio de 20I5). "Estancada la industria maderera en Quintana Roo". Novedades de Quintana Roo. Recuperado de: http://sipse.com/novedadstancada-I Romero, R., y Rioja, L. (20I2). "Frontera en conflicto. El diferendo limítrofe entre los estados peninsulares de Quintana Roo y Campeche, México, en el punto de unión territorial (PUT)" (presentación realizada en el XII Coloquio Internacional de Geocrítica). Universidad Nacional de Colombia. Bogotá: Colombia.

Rowley, C. K. (1993). Public Choice Theory. Inglaterra: The International Library of Critical Writings in Economics. Samaniego, G. (20 I0). Quintana Roo. Historia de las instituciones jurídicas. México: Universidad Nacional Autónoma de México, Instituto de Investigaciones Jurídicas.

SECTUR (29 de diciembre de 20I5).“'Información turística por entidad federativa”. Análisis Integral delTurismo, Secretaría de Turismo. Recuperado de: http://www.datatur.sectur. gob.mx/SitePages/InfTurxEdo.aspx

SHCP (29 de diciembre de 2016). “Aportaciones federales”. Secretaría de Hacienda y Crédito Público. Recuperado de: http://hacienda.gob.mx/ApartadosHaciendaParaTodos/ aportaciones/33/aportaciones.html 
Bibliografía

Skoopol,T. (1992). Protecting Soldiers and Mothers: The Political Origins of Social Policy in the United States. Cambridge: Cambridge University Press.

Steinmo, S., Thelen, K., y Longstreth, F. (1992). Structuring Politics: Historical Institutionalism in Comparative Analysis. Nueva York: Cambridge University Press.

Suárez, R. (2016).“Escenario estatal de las finanzas públicas”. Instituto Mexicano para la Competitividad. Recuperado de: http://imco.org.mx/politica_buen_gobierno/escenarioestatal-de-las-finanzas-publicas/

Tépach, R. (20I5). La deuda pública de las entidades federativas explicada desde la perspectiva del federalismo mexicano (informe legislativo presentado por la Dirección de servicios de investigación y análisis). Recuperado de: http:// www.diputados.gob.mx/sedia/sia/se/SAE-ISS- I 7-I2.pdf

Thelen, K.( (1999)."Historical Institutionalism in comparative politics". Annual Review of Political Science, 2, 369-404. doi: I0.I I46/annurev.polisci.2.1.369

Varillas, A. (II de mayo de 20I6a). "Frente a guerra sucia, voto útil: Carlos Joaquín”. El Universal. Recuperado de: http://www.eluniversal.com.mx/articulo/estados/2016/05/ I I/frente-guerra-sucia-en-qroo-voto-utilcarlos-joaquin

(23 de mayo de 2016b). "Reportan detenciones en Yucatán por 'turismo electoral'”. El Universal. Recuperado de: http://www.eluniversal.com.mx/articulo/ estados/2016/05/23/reportan-detenciones-en-yucatanpor-turismo-electoral 